\title{
An update on physiological effects of stress
}

\begin{abstract}
The awareness of stress was increased after World War II when it was noticed that many routine life events like examinations, growing up increases stress and leads to dysfunction. Stress has both positive and negative impact. Up to a limited level of threshold, stress may be beneficial. However, beyond this level, there will be sharp fall in the productivity. The current article reviews the effect of stress on different body systems. Stress contributes to development of many diseases and consequently decreases quality of life. As stress is unavoidable in present day life style, it must be managed effectively to improve the quality of life. Hence it is essential to understand the effects of stress on different body systems to develop effective interventions for stress management.
\end{abstract}

Keywords: stress, physiological effects, quality of life
Volume 6 Issue 2 - 2019

\author{
Kumar Sai Sailesh,' Srilatha B2 \\ 'Department of Physiology, Vishnu Dental College, India \\ ${ }^{2}$ Department of Biochemistry, Apollo Institute of Medical \\ Sciences and Research, India
}

Correspondence: Sai Sailesh Kumar G,Assistant Professor \& HOD (I/C), Department of Physiology,Vishnu Dental College, Bhimavaram, Andhra Pradesh, India,

Email dr.saisailesh@gmail.com

Received: February 20, 2019 | Published: March 20, 2019

\section{Introduction}

The awareness of stress was increased after World War II when it was noticed that many routine life events like examinations, growing up increases stress and leads to dysfunction. ${ }^{1}$ The word stress was used by Hans Selye for the first time in 1936 to explain the effects of threats that disturbs homeostasis. ${ }^{2,3}$ Walter B. Cannon explained the role of adrenal glands and sympathetic nervous system in maintenance of body equilibrium after exposure to threat. Hans Selye ${ }^{3}$ defined stress as a set of non-specific responses collectively called as "General Adaptation Syndrome". Hans Selye's theory of non-specificity was criticized by Mason ${ }^{4}$ Goldstein ${ }^{5}$ defined stress as "stress is a condition in which expectations, whether genetically programmed, established by prior learning or deduced from circumstances, do not match the current or anticipated perceptions of the internal or external environment and this discrepancy between what is observed or sensed and what is expected or programmed elicits patterned, compensatory responses". Later the word allostasis was introduced to stress research, which is the process of adaptation to different stressors. When there is any defect in the process of adaptation, it leads to "allostatic load or overload". ${ }^{6}$ Stress may be acute or episodic acute or chronic stress, which varies in characteristics, symptoms, duration and management approaches. The most commonly experienced stress is acute stress. Emotional distress, muscular, gastro intestinal problems, hypertension, tachycardia, decrease in the respiratory rate are symptoms of acute stress. Episodic acute stress is more common in people who regularly experience acute stress. Prolonged depression, anxiety and distress, coronary heart disease is most common symptoms of episodic acute stress. Long term exposure to stressor leads to chronic stress. Chronic stress is hazardous as it increases suicidal tendency. As acute stress is short-term, people are aware of it, but they may be unaware of chronic stress. $^{7}$ Stress has both positive and negative impact. Up to a limited level of threshold, stress may be beneficial. However, beyond this level, there will be sharp fall in the productivity. Hence, one should be aware of the indicators of stress. Common indicators of stress are irritability, insomnia, anxiety and/or feeling of giving up. However, the peak level of stress and indicators of stress varies from person to person. Considering these facts, Hans Selye ${ }^{3}$ stated that 'eustress' or 'good stress' increases productivity and 'distress' or 'bad stress' decreases the productivity. Eustress is required as it helps to complete a task; in contrast, distress may lead to depression. The current article reviews the effect of stress on different body systems.

\section{Physiological effects of stress}

Though stress originates in the brain, it affects all body systems including nervous, cardiovascular, respiratory, musculoskeletal, immune, gastrointestinal, endocrine and reproductive systems. ${ }^{8}$

\section{Effect of stress on nervous system}

The stress system not only triggers the fight or flight response through sympathetic nervous system, but also interacts with mesocortical and mesolimbic components of dopaminergic system, the amygdala/ hippocampus complex and the arcuate nucleus proopiomelanocortin neuronal system. ${ }^{9}$ Mesocortical and mesolimbic system forms the reward system and mediates euphoria and dysphoria. ${ }^{2}$ Stress activates amygdala/hippocampus system, which activates central stress system and mesocorticolimbic dopaminergic system. Corticotropin-releasing hormone neurons of amygdala are connected to paraventricular nuclei and parabrachial nucleus and elicit autonomic and behavioral effects. Activation of hippocampus causes shutting off of stress response by inhibiting PVN, CRH and LC/NE system. ${ }^{10}$ Stress induces release of opioid peptides especially $\alpha$-melanocyte-stimulating hormone and $\beta$-endorphin from hypothalamus. Both the opioid peptides inhibit components of central stress system. ${ }^{9}$

\section{Effect of stress on cardiovascular system}

Stress induced cardiovascular diseases include hypertension, myocardial ischaemia, myocardial infarction, ventricular arrhythmia, and sudden cardiac death. ${ }^{11}$ Stress causes hazardous effects on cardiovascular system through activation of sympathetic nervous system and vagal withdrawal. Stress induces certain mechanisms like rapid increase in arterial pressure and heart rate, increased serum lipid levels, altered blood coagulation, atherosclerosis and vascular changes that may lead to cardiovascular diseases. ${ }^{12-14}$

\section{Effect of stress on respiratory system}

Stress also induces respiratory changes like increase in respiratory rate and decrease in end-tidal Carbon dioxide that is hyperventilation. ${ }^{15}$ Changes in respiratory quotient and energy expenditure were observed in stressful conditions. However, the change depends on type of the stress. ${ }^{16}$ Stress influences respiration through modulating the activity of respiratory neurons. Excessive stress alters the membrane properties, strength of neuro-modulation in respiratory neurons. ${ }^{17}$ 


\section{Effect of stress on musculoskeletal system}

Increase in muscle tension is a reflex phenomenon to protect an individual from injury and pain. However chronic exposure to stress causes prolonged increase in muscle tension and promotes musculoskeletal disorders..$^{18}$ The muscles of shoulders, muscles of the neck and jaw, accessory muscles of respiration and diaphragm are commonly affected due to stress. ${ }^{19}$

\section{Effect of stress on blood}

Stress induced changes in blood cell parameters are well documented. ${ }^{20}$ It was studied that, stress induced release of cortisol decreases the eosinophils by increasing their sequestration in spleen and also decreases the number of basophils whereas stress increases number of neutrophils, platelets and red blood cells. ${ }^{21}$

\section{Effect of stress on immune system}

Activation of HPA axis during stress modulates both innate and adaptive immunity through increase in secretion of glucocorticoids. Cortisol modulates number and function of leucocytes, decreases production of cytokines, inhibits pro-inflammatory pathways in target tissues. Hence, chronic activation of HPA axis increases susceptibility to infections and tumors. Activation of autonomic system during stress has direct suppressive action on immune cells/organs. Glucocorticoids and catecholamines modulate balance between $\mathrm{T}$ helper-1 versus $\mathrm{T}$ helper-2 responses. ${ }^{22,23}$

\section{Effect of stress on gastro intestinal system}

Stress suppresses gastric emptying by inhibiting dorsal vagal complex and increases colonic motor activity through stimulation of sacral parasympathetic system. Further stress weakens gastro intestinal barrier and increases gastrointestinal permeability and contributes to inflammatory bowel disease. Chronic stress decreases pain threshold for visceral sensations in patients with gastro intestinal disorders. ${ }^{24-27}$ Stress has negative impact on oral health as there is a decrease in the salivary flow rates, total protein concentration was observed in stressful conditions. ${ }^{28}$ Further, stress contributes to increase in the salivary cortisol and $\mathrm{PH} .{ }^{29}$

\section{Effect of stress on metabolism}

Stress increases catabolism of glucose, lipids and proteins and simultaneously inhibits anabolic actions of growth hormone, insulin and sex steroids. This action of stress may be beneficial for short term basis to cope up with stressor. However, chronic activation of stress axis leads to metabolic syndrome through activation of HPA, LC/ NE sympathetic adrenal system and changes in health behavior. HPA axis activation increases gluconeogenesis in liver, increases plasma glucose levels, increases lipolysis, increases protein breakdown at skeletal muscles, bone and skin, which leads to visceral obesity, insulin resistance, atherosclerosis, decreases osteoblastic activity, muscle and bone mass. Further, chronic stress causes changes in physical activity like following sedentary life style, increased sleeping hours, changes in diet habits, which further worsen regulation of metabolic functions and increases the incidence of metabolic syndrome. ${ }^{30-33}$

\section{Effect of stress on endocrine system}

Stimulation of pituitary-adrenal axis in stress increases secretion of corticotrophin releasing hormone $(\mathrm{CRH})$ which increases secretion of adrenocorticotropin (ACTH), 8-lipotropin and 3-endorphin.
Increase in vasopressin secretion during stress potentiates the effect of CRH. Stress decreases levels of thyroid hormones through inhibition of thyroid-stimulating hormone secretion. Increase in the growth hormone secretion was reported followed by physical stress. GH responses for psychological stress was not well reported. Prolactin levels may increase or decrease during stress depending on local regulatory mechanisms. However, the role of altered prolactin levels is still unclear. Decrease in insulin secretion was observed in stress which may contribute for stress induced increase in blood glucose levels. ${ }^{34-40}$

\section{Effect of stress on reproductive system}

Though stress was reported to have negative impact on reproductive system, but the underlying mechanism was not clear. $\mathrm{CRH}$ and glucocorticoids exerts inhibitory effect on gonadotropinreleasing hormone $(\mathrm{GnRH})$ neurons, pituitary gonadotrophs and gonads directly and indirectly. As a result, the production of steroid hormones will be decreased at gonads that lead to amenorrhea of stress in females and decreased libido and hypo-fertility in males. ${ }^{41,42}$

\section{Conclusion}

Stress contributes to development of many diseases and consequently decreases quality of life. As stress is unavoidable in present day life style, it must be managed effectively to improve the quality of life. Hence it is essential to understand the effects of stress on different body systems to develop effective interventions for stress management.

\section{Acknowledgments}

None.

\section{Conflicts of interest}

The authors declare there is no conflicts of interest.

\section{References}

1. Lazarus RS. From psychological stress to the emotions: a history of changing outlooks. Annu Rev Psychol. 1993;44:1-22.

2. Chrousos GP. The concepts of stress and stress system disorders: overview of physical and behavioral homeostasis. J Am Med Assn. 1992;267(9):1244-1252.

3. Selye H. The stress of life. New York: McGraw-Hill; 1978.

4. Mason JW. A re-evaluation of the concept of" non-specificity" in stress theory. J Psychiatr Res. 1971;8(3):323-333.

5. Goldstein DS, Kopin IJ. Evolution of concepts of stress. Stress. 2007;10(2):109-120.

6. McEwen BS. Stress, adaptation, and disease. Allostasis and allostatic load. Ann NY Acad Sci. 1998;840:33-44.

7. Miller LH, Smith AD, Rothstein L. The stress solution: an action plan to manage the stress in your life. New York: Pocket Books; 1994.

8. McEwen BS. Central effects of stress hormones in health and disease: Understanding the protective and damaging effects of stress and stress mediators. Eur J Pharmacol. 2008;58(2-3):174-185.

9. Tsigos C, Chrousos GP. Hypothalamic-pituitary-adrenal axis, neuroendocrine factors and stress. J Psychosom Res. 2002;53(4):865871 . 
10. McEwen BS. Physiology and neurobiology of stress and adaptation: central role of the brain. Physiol Rev. 2007;87(3):873-904.

11. Steptoe A, Kivimäki M. Stress and cardiovascular disease. Nat Rev Cardiol. 2012;9(6):360-370.

12. Engler MB, Engler MM. Assessment of the cardiovascular effects of stress. J Cardiovasc Nurs. 1995;10(1):51-63.

13. Lucini D, Norbiato G, Clerici M, et al. Hemodynamic and autonomic adjustments to real life stress conditions in humans. Hypertension. 2002;39(1):184-188.

14. Vale S. Psychosocial stress and cardiovascular diseases. Postgrad Med J. 2005;81(957):429-435.

15. Levitt MA, Derrick GR. An evaluation of physiological parameters of stress in the emergency department. Am J Emerg Med. 1991;9(3):217219.

16. McGregor IS, Lee AM, Westbrook RF. Stress-induced changes in respiratory quotient, energy expenditure and locomotor activity in rats: effects of midazolam. Psychopharmacology (Berl). 1994;116(4):475482 .

17. Kinkead R, Dupenloup L, Valois N, et al. Stress-induced attenuation of the hypercapnic ventilatory response in awake rats. $J$ Appl Physiol. 2001;90(5):1729-1735

18. Lindegard A, Larsman P, Hadzibajramovic E, et al. The influence of perceived stress and musculoskeletal pain on work performance and work ability in Swedish health care workers. Int Arch Occup Environ Health. 2014;87(4):373-379.

19. Cielo CA, Christmann MK, Ribeiro VV, et al. Musculoskeletal stress syndrome, extrinsic laryngeal muscles and body posture: theoretical considerations. Rev CEFAC. 2014;16:1639-1649.

20. Qureshi F, Alam J, Khan MA, et al. Effect of examination stress on blood cell parameters of students in a Pakistani medical college. J Ayub Med Coll Abbottabad. 2002;14(1):20-22.

21. Barrett KE, Ganong WF. Ganong's review of medical physiology. 23rd ed. New York: McGraw-Hill Medical; 2010:1-727.

22. Chrousos GP. The stress response and immune function: clinical implications. The 1999 Novera H. Spector Lecture. Ann N Y Acad Sci. 2000;917:38-67.

23. Charmandari E, Kino T, Chrousos GP. Glucocorticoids and their actions: an introduction. Ann NY Acad Sci. 2004;1024:1-8.

24. Drossman DA. Physical and sexual abuse and gastrointestinal illness: what is the link? Am J Med. 1994;97(2):105-107.

25. Scarinci IC, McDonald-Haile J, Bradley LA, et al. Altered pain perception and psychosocial features among women with gastrointestinal disorders and history of abuse: a preliminary model. Am J Med. 1994;97:108-118.

26. Collins SM. Stress and the Gastrointestinal Tract IV. Modulation of intestinal inflammation by stress: basic mechanisms and clinical relevance. Am J Physiol Gastrointest Liver Physiol. 2001;280(3):G315G318.
27. Stengel A, Wang L, Taché Y. Stress-related alterations of acyl and desacyl ghrelin circulating levels: mechanisms and functional implications. Peptides. 2011;32(11):2208-2217.

28. Matos-Gomes N, Katsurayama M, Makimoto FH, et al. Psychological stress and its influence on salivary flow rate, total protein concentration and IgA, IgG and IgM titers. Neuroimmunomodulation. 2010;17(6):396404.

29. Naumova EA, Sandulescu T, Bochnig C, et al. Dynamic changes in saliva after acute mental stress. Sci Rep. 2014;4:4884.

30. Cavagnini F, Croci M, Putignano P, et al. Glucocorticoids and neuroendocrine function. Int J Obes Relat Metab Disord. 2000;24 Suppl 2:S77-S79.

31. Kyrou I, Tsigos C. Stress mechanisms and metabolic complications Horm Metab Res. 2007;39(6):430-438.

32. Grippo AJ, Johnson AK. Stress, depression and cardiovascular dysregulation: a review of neurobiological mechanisms and the integration of research from preclinical disease models. Stress. 2009;12(1):1-21.

33. Tamashiro KL, Sakai RR, Shively CA, et al. Chronic stress, metabolism, and metabolic syndrome. Stress Amst Neth. 2011;14(5):468-474.

34. Herman JP, Figueiredo H, Mueller NK, et al. Central mechanisms of stress integration: hierarchical circuitry controlling hypothalamopituitary-adrenocortical responsiveness. Front Neuroendocrinol. 2003;24(3):151-180.

35. Aguilera G, Subburaju S, Young S, et al. The parvocellular vasopressinergic system and responsiveness of the hypothalamic pituitary adrenal axis during chronic stress. Prog Brain Res. 2008;170:29-39.

36. Ranabir S, Reetu K. Stress and hormones. Indian J Endocrinol Metab. 2011;15(1):18-22.

37. Helmreich DL, Tylee D. Thyroid hormone regulation by stress and behavioral differences in adult male rats. Horm Behav. 2011;60(3):284 291.

38. Skuse D, Albanese A, Stanhope R, et al. A new stress-related syndrome of growth failure and hyperphagia in children, associated with reversibility of growth-hormone insufficiency. Lancet. 1996;348(9024):353-358.

39. Itoh N, Obata K, Yanaihara N, et al. Human preprovasoactive intestinal polypeptide contains a novel PHI-27-like peptide, PHM-27. Nature. 1983;304(5926):547-549.

40. Halter JB, Beard JC, Porte D. Islet function and stress hyperglycemia: plasma glucose and epinephrine interaction. Am J Physiol. 1984;247(1 Pt 1):E47-E52.

41. Traslavina GA, Franci CR. The $\mathrm{CRH}-\mathrm{R}_{1}$ receptor mediates luteinizing hormone, prolactin, corticosterone and progesterone secretion induced by restraint stress in estrogen-primed rats. Brain Res. 2011;1421:11-19.

42. Whirledge S, Cidlowski JA. Glucocorticoids, stress, and fertility. Minerva Endocrinol. 2010;35(2):109-125. 